\title{
Pemanfaatan CPO (Crude Palm Oil) Untuk Desulfurisasi Pada Batubara Menggunakan Metode Flotasi
}

\author{
Danang Jaya*, M.Syahri, Ebeng Sugondo dan Yunita Nurindahsari
}

Program Studi Teknik Kimia UPN “Veteran” Yogyakarta

Jl SWK 104 Condongcatur, Yogyakarta, 55283

\section{Artikel histori :}

Diterima September 2016 Diterima dalam revisi Oktober 2016 Diterima November 2016 Online Juni 2017

\begin{abstract}
ABSTRAK: Sejalan dengan perkembangan pemanfaatan batubara di Indonesia, muncul pula beberapa kendala yang menghambat perkembangan tersebut yaitu adanya gas $\mathrm{SO}_{2}$ hasil pembakaran batubara yang dapat menimbulkan pencemaran udara. Flotasi adalah suatu proses untuk memisahkan padatan halus yang terpisah dari suatu padatan dengan padatan yang lain, secara umum diterapkan pada konsentrasi bijih logam, untuk membersihkan bahan bakar padat atau benefisiasi mineral bukan logam, tetapi juga dapat diterapkan untuk pemisahan padatan dari cairan atau pemisahan padatan non-mineral dari suatu padatan dengan padatan yang lain. Penelitian desulfurisasi pada batubara yang berasal dari bahan baku Pembangkit Listrik Tenaga Uap(PLTU) menggunakan metode flotasi dilakukan secara kontinyu dalam sebuah alat kolom flotasi. Disini beberapa variabel flotasi diantaranya adalah perbandingan antara batubara dengan Crude palm oil (CPO) yaitu 1:2, 1:4, 1:6 dengan laju alir umpan yang berbeda-beda. Diperoleh kondisi yang optimal pada pengurangan kadar sulfur pada proses flotasi ketika laju alir umpan sebesar 0,3612 L/menit dengan perbandingan $\mathrm{CPO} /$ Batubara pada 1:2 dengan sulfur yang terambil sebesar $45,269 \%$.
\end{abstract}

Kata Kunci: flotasi, kontinyu, perbandingan batubara dengan CPO, laju alir umpan, kadar sulfur

\begin{abstract}
Sulfur dioxide is one of toxic gas that is produced from coal burning process. Flotation is one of methods to separate particle from other particles. This research is aimed to reduce the sulfur content in coal that is used in power plant using flotation method combined with the addition of surfactant. Crude Palm Oil is conducted as surfactant. Coal and CPO is varied 1:2, 1:4, 1:6 (w/w) in a various flowrate. The optimum condition for the operation is found in the rate of flow $0,3612 \mathrm{~L} / \mathrm{min}$ with $\mathrm{CPO} /$ coal is $1: 2$, which contribute in sulphur removed up to $45,269 \%$.
\end{abstract}

Keywords: flotation; continuous; Coal/CPO; flowrate; sulphur

\section{Pendahuluan (Introduction)}

Potensi sumber utama di Indonesia saat ini adalah minyak bumi, gas alam dan batubara. Konsumsi batubara dunia mencapai 7,8 miliyar ton/tahun dan konsumsi domestik batubara Indonesia 80 juta ton atau $23 \%$ produksi nasional. Pada tahun 2030 konsumsi batubara nasional diperkirakan mencapai 781 juta ton/tahun yang sebagian besar diperuntukkan sebagai bahan bakar PLTU yakni sekitar 250 juta ton (Anonim,2012). Batubara adalah salah satu bahan bakar fosil. Yang terbentuk dari endapan organik dimana unsur-unsur utamanya terdiri dari karbon, hidrogen dan oksigen. Cara terbentuknya batubara melalui proses yang sangat panjang dan lama, disamping dipengaruhi faktor alamiah yang tidak mengenal batas waktu, terutama ditinjau dari segi fisika, kimia maupun biologis.

\footnotetext{
Corresponding Author:

Email: danangjay@yahoo.co.id
}

Sejalan dengan perkembangan pemanfaatan batubara di Indonesia, muncul pula beberapa kendala yang menghambat perkembangan tersebut. Kendala utama tersebut adalah adanya gas $\mathrm{SO}_{2}$ hasil pembakaran batubara yang dapat menimbulkan pencemaran udara. Penggunaan batubara dengan kadar sulfur diatas $0,44 \%$ berat (dasar kering) dan pembakaran dengan ekses 5\% akan menghasilkan emisi SO2 diatas baku mutu lingkungan. (Cahyadi,2006). Untuk mengurangi gas $\mathrm{SO}_{2}$ ini dapat dilakukan dengan mengurangi kandungan sulfur sebelum batubara dibakar atau dengan mengurangi kandungan sulfur setelah batubara dibakar. Dalam usaha meningkatkan kualitas batubara ,termasuk menurunkan kadar sulfur untuk menuju Teknologi batubara bersih (TBB), maka berbagai teknologi desulfurisasi telah dan sedang dikembangkan (Achmad Roesyadi dkk, 2005).

Desulfurisasi adalah usaha yang dilakukan untuk memperbaiki kualitas batubara, agar batubara tersebut memenuhi syarat penggunaanya. Pencucian batubara bertujuan untuk memisahkan dari material pengotornya 
dalam upaya meningkatkan kualitas batubara sehingga nilai panas bertambah dan kandungan air serta debu berkurang. Untuk menentukan metode desulfurisasi batubara yang tepat maka perlu identifikasi jenis sulfur dan ikatan kimia dalam batubara tersebut. Ikatan sulfur dalam senyawa organik merupakan ikatan kovalen, seperti pada merkaptan dan tiol (R-S-H), disulfide (R-S-S-R) sebagaimana digambarkan dalam struktur batubara menurut model Wiser (Krevelen,1993). Pada dasarnya proses pemisahan secara flotasi adalah sangat kompleks karena banyak parameter operasi yang berpengaruh. Secara umum dapat disebutkan parameter-parameter tersebut ditinjau dari dua faktor utama yaitu faktor fisika dan faktor kimia. Faktor fisika seperti desain sel, dimensi kolom, pengadukan, laju alir udara,ukuran butiran partikel dan ukuran gelembung udara serta faktor kimia seperti $\mathrm{pH}$, reagent, dan konsentrasi slurry (Brown, 1973). Flotasi adalah suatu proses untuk memisahkan padatan halus yang terpisah dari suatu padatan dengan padatan yang lain. Secara umum diterapkan pada konsentrasi bijih logam, untuk membersihkan bahan bakar padat atau benefisiasi mineral bukan logam, tetapi juga dapat diterapkan untuk pemisahan padatan dari cairan atau pemisahan padatan non-mineral dari suatu padatan dengan padatan yang lain. Pemisahan flotasi dari padatan yang berbeda dapat diselesaikan dengan afinitas selektif dari permukaan padatan, baik dimodifikasi oleh reagen dengan bantuan gelembung udara dan air atau pun tidak. Dari berbagai tahapan, fase gas adalah yang paling sederhana dan fase padat yang paling beragam. Pada fasa cairan meskipun terlihat sederhana tetapi sebenarnya kompleks dan penting. Fase gas dalam flotasi selalu ada dan sifatnya paling penting dalam flotasi karena menimbulkan daya apung dari gelembung udara sehingga partikel mineral dapat diangkat oleh buih. Tampaknya daya apung dari gelembung udara akan semakin baik apabila udara atau gas berada pada tekanan atmosfer atau pada tekanan vakum. Fase cair dalam flotasi selalu berbentuk larutan dan umumnya encer, ada alasan yang baik mengapa larutan yang sering digunakan dalam proses flotasi itu adalah air, dikarenakan air selalu tersedia, murah, dan sangat cocok untuk kinerja proses flotasi.

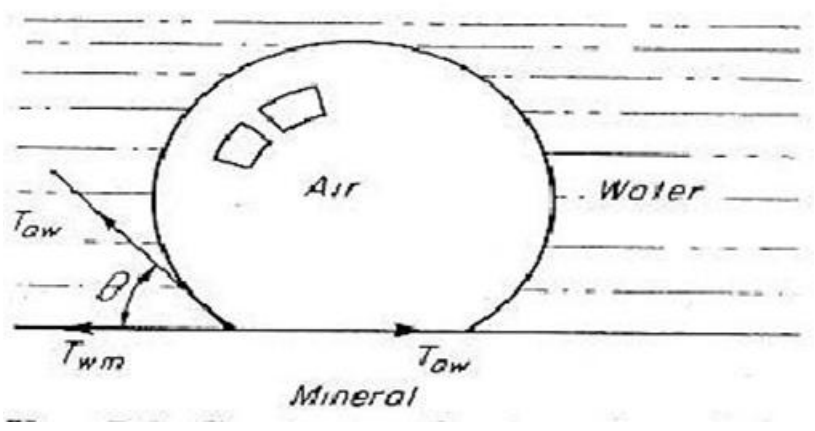

Gambar 1.Sudut kontak antara mineral-udara dan air.(Gaudin, 1957)

Sifat flotasi pada fase padat dapat ditentukan dari karakter pada permukaan padat tersebut tetapi untuk mengevaluasi permukaan padatan penting untuk mempertimbangkan bagian dalam permukannya dan dapat diasumsikan jauh diperluas disemua arah. Kebanyakan padatan berbentuk atom dan molekul yang memiliki titik leleh sangat rendah.

Sudut kontak dalam proses flotasi dapat diartikan sebagai dua fase berada dalam kontak bersama antar muka didalam dua dimensi. Setelah itu tiga fase datang akan bersama-sama, didalam satu garis dimensi sehingga kontak akan terbentuk. Sifat-sifat garis kontak yang terbaik dapat dinyatakan dalam sudut yang terbentuk oleh permukaan yang bergabung dalam arah tegak lurus dalam garis kontak. Sudut kontak dapat dinyatakan apabila sistem tersebut diukur pada air. Jika sudut kontak pada mineral tidak terjadi, ini berarti bahwa air dalam bentuk gelembung udara yang tidak dapat membasahi mineral sehingga sangat mustahil untuk berkontaknya udara dengan mineral. Sudut kontak bernilai nol derajat mewakili nonflotability. Gaya adhesi pada gelembung udara ke padatan terjadi secara spontan bahkan ketika sudut kontak kurang dari $90^{\circ}$, dan dinyatakan dalam konfigurasi geometris yang sesuai,ini dapat terjadi sepanjang waktu di proses flotasi. Gaya adhesi tidak dapat bekerja jika sudut kontak yang terbentuk telah mencapai $90^{\circ}$.

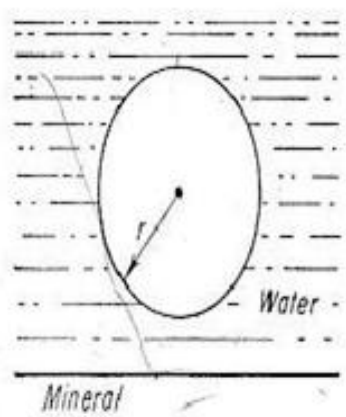

Initial condition

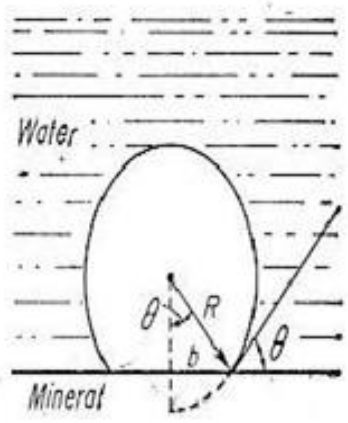

Terminal condition
Gambar 2. Gaya adhesi pada mineral batubara (Gaudin, 1957)

Jika suatu sistem yang terdiri dari gelembung gas dan partikel padat yang tersuspensi secara terpisah maka perubahan air untuk suatu sistem yang terdiri dari gelembung gas akan menempel pada partikel didalam air , sehingga terjadi perubahan energi. Ini dapat dilihat dari tiga energi antar muka dan dari perubahan dalam jumlah tiga bidang antar muka (Gaudin, 1957). Melalui pengenalan eksperimental, sudut kontak mineral yang keras dapat terukur dan energi dari mineral gas permukaan yang tidak diketahui dapat dihilangkan.. Secara umum pelepasan sulfur pada batubara sebagai berikut : sulfur dalam batubara berbentuk pirit $\left(\mathrm{FeS}_{2}\right)$ terlebih dahulu mengalami ionisasi (parsial) membentuk molekul polar dengan adanya ion asam $\left(\mathrm{H}^{+}\right)$dengan reaksi:

$\mathrm{H}^{+}+: \mathrm{FeS}_{2} \rightarrow \mathrm{H}^{2} \mathrm{Fe}^{+} \mathrm{S}_{2}$

Pirit dalam bentuk terionkan ini $\left(\mathrm{H}^{+}: \mathrm{FeS}_{2}\right)$ akan bersifat lebih hidrofilik sehingga lebih mudah tertarik dengan kompinen hidrofilik lainnya (air):

$\mathrm{H}_{2} \mathrm{O}:+\mathrm{H}_{\mathrm{s}} \mathrm{Fe}^{+} \mathrm{S}_{2} \rightarrow \mathrm{H}_{\mathrm{a}} \mathrm{O}^{+}+\mathrm{FeS}_{2}$ 
dan karenanya akan lebih mudah dipisahkan dari campuran batubara (komponen hidrofobik). Sebaliknya adanya ion $\mathrm{OH}^{-}$dalam campuran slurry (kondisi basa), tidak meningkatkan kehidrofilikan pirit, bahkan ion $\mathrm{OH}^{-}$(yang bermuatan negatif) cenderung tolak menolak dengan molekul pirit yang yang bermuatan negatif parsial (atom $\mathrm{Fe}$ dalam pirit memiliki pasangan elektron bebas pada kulit terluarnya dan bersifat elektronegatif). Akibatnya pirit sulit ditarik dari campuran batubara yang bersifat basa tersebut. Untuk mendapatkan hasil maksimum desulfurisasi batubara secara flotasi, maka perlu dilakukan pada kondisi-kondisi yang optimum. Untuk mendapatkan hasil maksimum desulfurisasi batubara secara flotasi, maka perlu dilakukan pada kondisi-kondisi yang optimum. Untuk memudahkan pemisahan dengan metode flotasi biasanya ditambahkan flotating agent berupa kolektor kedalam sistem flotasi dan berfungsi sebagai surfaktan, dimaksudkan untuk menurunkan tegangan permukaan antara partikel padatudara. Penurunan tegangan tersebut menyebabkan peningkatan gaya adhesi antara partikel padat dengan permukaan gelembung udara, sehingga partikel padat mudah terflotasi bersama gelembung udara. Surfaktan juga dapat berperan meningkatkan derajad kehidrofobian suatu partikel. Senyawa sabun dari CPO kelapa sawit dapat berfungsi sebagai surfaktan (Aladin , 2009).

Suatu kolektor dalam sistem flotasi akan efektif berinteraksi dengan partikel yang akan dihidrofillikkan pada kondisi $\mathrm{pH}$ tertentu. Setiap mineral dapat terflotasi secara optimal pada $\mathrm{pH}$ kritis. Jika $\mathrm{pH}$ kritis bergeser maka flotasi dapat gagal. Untuk memudahkan pemisahan flotability, biasanya ditambahkan flotating agent berupa kolektor kedalam sistem flotasi dan berfungsi sebagai surfaktan, dimaksudkan untuk menurunkan tegangan permukaan antara partikel padat-udara. Penurunan tegangan tersebut menyebabkan peningkatan gaya adhesi antara partikel padat dengan permukaan gelembung udara, sehingga partikel padat mudah terflotasi bersama gelembung udara.Surfaktan juga dapat berperan meningkatkan derajad kehidrofobian suatu partikel. (Aladin,2009).

\subsection{Macam-Macam Reagen Flotasi}

Keberhasilan proses flotasi sangat ditentukan oleh ketetapan penggunaan reagent, baik jumlah maupun jenisnya. Reagen flotasi yang ditambahkan pada tahap conditioning dengan tujuan menciptakan suatu pulp yang kondisinya sesuai agar dapat dilakukan flotasi dan mineral yang diinginkan dapat terapungkan sebagai konsentrat.

Berikut beberapa jenis reagen yang digunakan pada proses flotasi:

\section{- Collector (collecting agent, promotor)}

Adalah suatu reagen yang memberikan sifat menempel pada udara sehingga mineral tersebut senang pada udara. Collector merupakan zat organik dalam bentuk asam, basa atau garam yang berbentuk heteropolar, yaitu satu ujungnya senang pada air dan ujung lainnya senang pada udara. Molekul kolektor berupa senyawa yang dapat terionisasi menjadi ion-ion dalam air (ionizing collector) atau berupa senyawa yang tidak dapat terionisasi dalam air (non ionizing collector. Macam kolektor antara lain : Xanthat, Aerofloat, Thio carbonalit (urae), Fatty acid (asam lemak), Oleic acid, dan Palmatic acid

\section{- Conditioner/Modifier}

Merupakan suatu reagent, bila ditambahkan ke dalam pulp akan memberikan pengaruh tertentu terhadap air atau mineral agar dapat membantu atau menghalangi kerja dari collector. Pengaruh umum yang dihasilkan adalah memperkuat atau memperlemah hydrophobisitas dari suatu permukaan mineral tertentu. Modifier ini biasanya anorganik.

\section{- Frother}

Merupakan suatu zat organik hydrocarbon yang terdiri dari polar dan non polar. Fungsi reagent ini untuk menstabilkan gelembung udara agar dapat sampai ke permukaan. Zat tersebut menyelimuti gelembung udara sehingga tegangan permukaan air akan menjadi lebih rendah, sehingga akan timbul gelembung udara. Molekul frother adalah heteropolar, terdiri dari gugusan hydroxyl bersifat polar yang menarik air dan rantai hidrokarbon sebagai gugusan non polar. Macam- macam frother antara lain: Methyl amil alcohol, Methyl iso butil carbinol, Cresitic acid, Pine oil, Polyprophylene glycol ether,dan Thricthoxy butane.(Anonim,2012)

\subsection{Pemilihan surfactant dari CPO}

Indonesia merupakan negara produsen kelapa sawit terbesar kedua di dunia setelah Malaysia. Produksinya hingga tahun 2014 mencapai 29,5 juta ton dan diperkirakan untuk tahun 2015 bisa mencapai 31 juta ton. Sebanyak $43 \%$ CPO di dalam daging buah sawit yang terdiri dari berbagai asam lemak, seperti asam palmitat, asam oleat, asam linoleat, asam stearat dan asam miristat. Surfaktan adalah suatu molekul yang sekaligus memiliki gugus hidrofilik dan gugus hidrofobik sehingga dapat mempersatukan campuran yang terdiri dari air dan minyak. Aktifitas surfaktan diperoleh karena sifat ganda dari molekulnya yang memiliki bagian polar yang suka akan air (hidrofilik) dan bagian nonpolar (hidrofobik). Bagian polar molekul surfaktan dapat bermuatan positif, negatif atau netral. Sifat rangkap ini menyebabkan surfaktan dapat di adsorbsi pada antar muka udara-air, zat padat-air, membentuk lapisan tunggal dimana gugus hidrofilik berada fase air dan rantai hidrokarbon ke udara, dalam kontak dengan zat padat atau terendam dalam fase minyak. Umumnya bagian non polar (hidrofobik) adalah rantai alkil yang panjang sementara bagian yang polar (hidrofilik) mengandung gugus hidroksil. Senyawa sabun asam lemak (RCOONa) pada CPO dapat digunakan sebagai surfaktan dalam proses flotasi, mengingat struktur senyawa ini terdiri dari gugus anion (COO-) yang bersifat polar (hidrofilik) dan gugus rantai karbon (R) yang bersifat non polar (hidrofobik). Senyawa sabun tersebut dapat dihidrolisis basa dari minyak/lemak kasar kelapa sawit (CPO). Pada umumnya bilangan penyabunan CPO tergolong cukup tinggi yaitu sebesar 204,4 yang menunjukan kuantitas sabun asam lemak dalam CPO relatif tinggi dan sangat baik 
untuk proses flotasi. Berdasarkan reaksi berikut sabun asam lemak dari CPO dapat berfungsi dengan ganda baik sebagai kolektor maupun sebagai froter dalam sistem flotasi busa. Berikut reaksi pada crude palm oil (CPO).

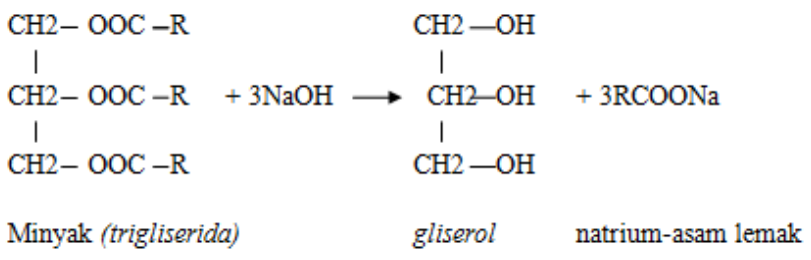

Gambar 3. Reaksi kimia pada CPO

Pada penelitian yang telah dilaksakan CPO didapat dari PT.PP London Sumatera, Tbk yang ada di Kabupaten Langkat, Provinsi Sumatera Utara.

\section{Metode Penelitian}

\subsection{Bahan Penelitian}

Bahan-bahan yang digunakan dalam penelitian ini antara lain : Minyak kelapa sawit mentah (CPO), Boraks, $\mathrm{Na}_{2} \mathrm{CO}_{3}$ 2M, MO,HCL 1M, Air, Batubara coklat.

\subsection{Alat Penelitian}

Alat-alat yang digunakan dalam penelitian ini antara lain : Piknometer, Labu ukur, Gelas ukur 1000 ml, Pengaduk, Neraca analitik, Gelas beker, Ayakan, kertas saring, Erlenmeyer, Corong, Kertas PH, Stop watch, Gelas arloji, Wadah penampung, pompa, aerator dengan laju alir 1,25 $\mathrm{L} /$ menit, kolom flotasi dengan panjang $90 \mathrm{~cm}$ dan diameter 2,5 inchi.

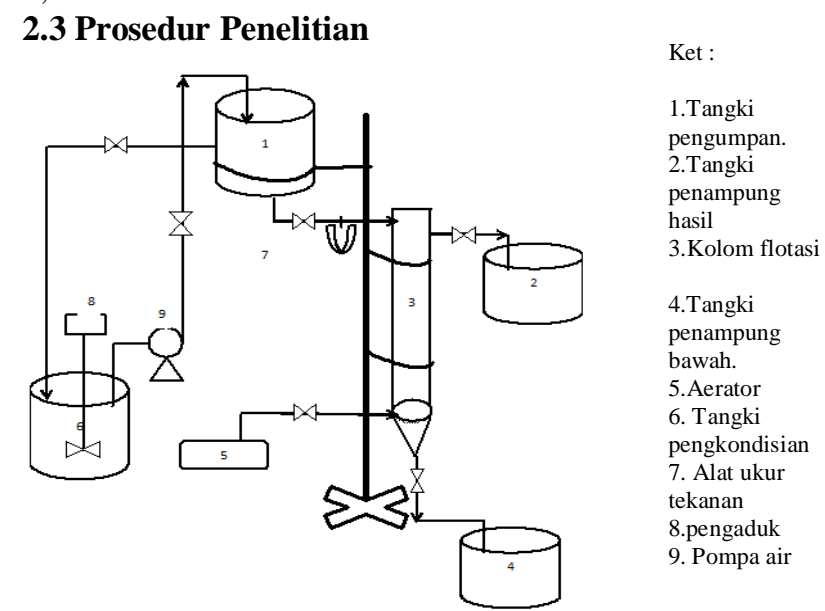

Gambar 4. Rangkaian Alat Penelitian

Batubara coklat yang berupa bongkahan dikecilkan ukurannya. Selanjutnya batubara coklat tersebut di ayak menggunakan ayakan berukuran 100 mesh. Kemudian batubara dengan ukuran 100 mesh tersebut ditimbang sebanyak 275 gram menggunakan neraca analitik. Untuk persiapan pengambilan sampel, selanjutnya didalam tangki pengkondisian mula-mula berisi air sebanyak 5 liter, kemudian dicampurkan dengan CPO pada variasi $1: 2,1$ : 4, dan 1 : 6 (berat/berat) terhadap batubara, lalu ditambahkan $\mathrm{Na}_{2} \mathrm{CO}_{3} 2 \mathrm{M}$ sebanyak $50 \mathrm{ml}$, diaduk dan diatur PH nya menggunakan HCL $1 \mathrm{M}$, kemudian dimasukkan batubara dengan ukuran 100 mesh dan ditambahkan air hingga 25 liter. PH kembali dicek dan diatur agar tetap enam. Setelah campuran terkondisikan dengan baik maka dialirkan ke tangki pengumpan dengan kecepatan laju alir umpan yang berbeda-beda. Aerator dihidupkan dan udara dialirkan masuk kolom flotasi dan flotasi dibuat secara kontinyu sedemikian rupa. Lamanya proses flotasi pada batubara didalam kolom flotasi, berlangsung sesuai dengan waktu tinggal untuk masingmasing laju alir umpan yang telah ditentukan. Hasil batubara dibagian atas kolom ditampung untuk dianalisis menggunakan spektrofotometer UV-Vis. Flotasi diulangi untuk varian-varian yang telah ditentukan.

\section{Hasil dan Pembahasan}

Berdasarkan analisa batubara subituminus diperoleh kadar sulfur mula-mula sebesar 0,3636\% dalam 1 gr Batubara. Hasil penelitian variasi laju alir umpan dengan perbandingan CPO : Batubara dapat dilihat pada tabel dibawah ini :

1. Perbandingan CPO : Batubara $(1: 2)$

Tabel 3. Hubungan antara Laju alir umpan dengan sulfur terambil (\%)

\begin{tabular}{cc}
\hline $\begin{array}{c}\text { Laju alir umpan } \\
\text { (Liter/menit) }\end{array}$ & $\begin{array}{c}\text { Kadar sulfur yang } \\
\text { terambil }(\%)\end{array}$ \\
\hline 0,3612 & 45,269 \\
0,767 & 40,8267 \\
1,3026 & 29,5142 \\
1,8133 & 29,3007 \\
\hline
\end{tabular}

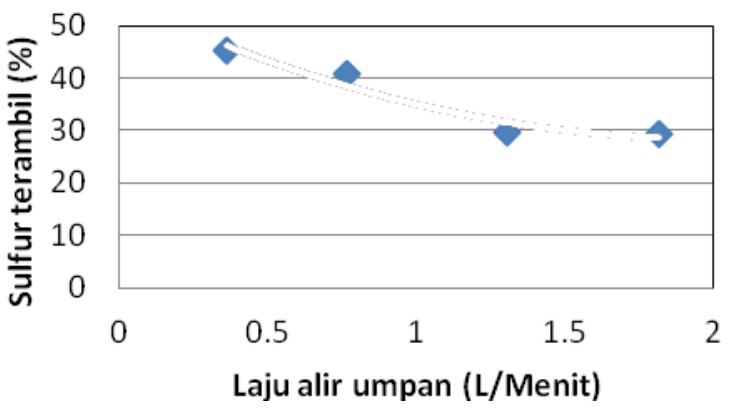

Gambar 5. Hubungan antara Laju alir umpan dengan Sulfur terambil (\%)

Dari tabel 3 dan gambar 5 diatas, terlihat bahwa semakin cepat laju alir, maka kadar sulfur yang terambil pada batubara semakin kecil. Hal ini di karenakan waktu tinggal batubara pada kolom flotasi semakin cepat. Ini disebabkan bahwa untuk pemisahan sulfur (pirit) dari campuran batubara membutuhkan waktu kontak Secara umum pelepasan sulfur pada batubara sebagai berikut : sulfur dalam batubara berbentuk pirit $\left(\mathrm{FeS}_{2}\right)$ terlebih dahulu mengalami ionisasi (parsial) membentuk molekul polar dengan adanya ion asam $\left(\mathrm{H}^{+}\right)$dengan reaksi : 
$\mathrm{H}^{+}+: \mathrm{FeS}_{2} \rightarrow \mathrm{H}: \mathrm{Fe}^{+} \mathrm{S}_{2}$. Pirit dalam bentuk terionkan ini $\left(\mathrm{H}^{+}: \mathrm{FeS}_{2}\right)$ akan bersifat lebih hidrofilik sehingga lebih mudah tertarik dengan kompinen hidrofilik lainnya (air) $\left(\mathrm{H}_{2} \mathrm{O}:+\mathrm{H}^{\mathrm{F}} \mathrm{Fe}^{+} \mathrm{S}_{2} \rightarrow \mathrm{H}_{3} \mathrm{O}^{+}+\mathrm{FeS}_{2}\right)$ dan karenanya akan lebih mudah dipisahkan dari campuran batubara (komponen hidrofobik). Hasil optimal terjadi pada laju alir 0,3612 dengan kadar sulfur yang terambil sekitar $45,269 \%$.

\section{Perbandingan $\mathrm{CPO}:$ Batubara $(1: 4)$}

Tabel 4. Hubungan antara laju alir umpan(L/menit) dengan sulfur terambil (\%)

\begin{tabular}{cc}
\hline $\begin{array}{c}\text { Laju alir umpan } \\
\text { (Liter/menit) }\end{array}$ & $\begin{array}{c}\text { Kadar sulfur yang } \\
\text { terambil }(\%)\end{array}$ \\
\hline 0,3612 & 43,2643 \\
0,767 & 38,9319 \\
1,3026 & 28,0977 \\
1,8133 & 26,4713 \\
\hline
\end{tabular}

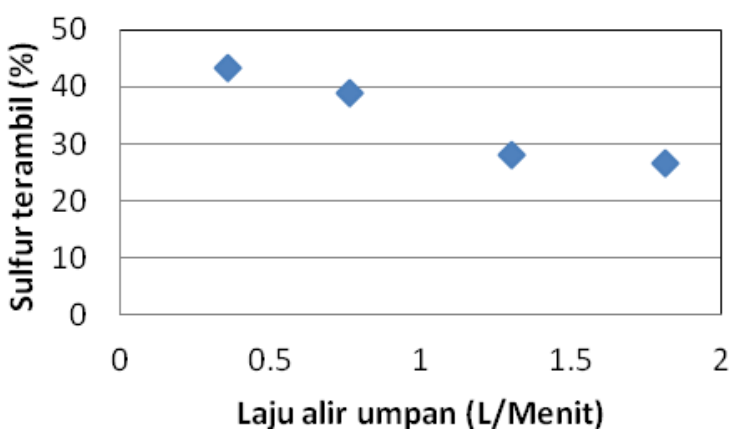

Gambar 6. Hubungan antara Laju alir umpan dengan Sulfur terambil $(\%)$

Dari tabel 4 dan gambar 6 diatas, terlihat bahwa semakin cepat laju alir maka, kadar sulfur yang terambil pada batubara semakin kecil ini di karenakan waktu tinggal batubara pada kolom flotasi semakin cepat. Berbanding terbalik dengan kecepatan laju alir yang lambat. Adanya komposisi yang pas tiap komponen dalam campuran slurry mengakibatkan batubara mudah terbasahi karena sudut kontak antara udara dengan mineral sulfur pada permukaann batubara dalam campuran slurry terbentuk kurang dari 90 derajat sehingga sulfur pada batubara secara anorganik mudah terlepas sehingga batubara bersih dapat terangkat oleh udara (fase gas) dari aerator. Hasil terbaik pada laju alir umpan sebesar 0,3612 dengan kadar sulfur sisa sebesar 43,2643\%.

\section{Perbandingan CPO : Batubara $(1: 6)$}

Tabel 5. Hubungan antara Laju alir umpan dengan sulfur terambil (\%)

\begin{tabular}{cc}
\hline $\begin{array}{c}\text { Laju alir umpan } \\
\text { (Liter/menit) }\end{array}$ & $\begin{array}{c}\text { Kadar sulfur yang } \\
\text { terambil }(\%)\end{array}$ \\
\hline 0,3612 & 42,1653 \\
0,767 & 36,1296 \\
1,3026 & 25,3515 \\
1,8133 & 26,0713 \\
\hline
\end{tabular}

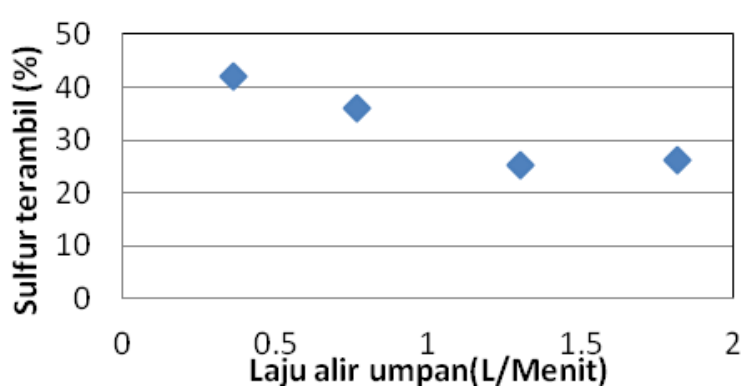

Gambar 7. Hubungan antara Laju alir umpan (L/Menit) dan Kadar sulfur (\%)

Dari tabel 5 dan gambar 7 diatas, terlihat bahwa semakin kecil laju alir umpan ,maka kadar sulfur yang terambil pada batubara akan semakin besar hal ini dikarenakan waktu tinggal batubara pada kolom flotasi lebih lama sehingga waktu kontak antara campuran slurry pada batubara dengan udara akan semakin lebih lama sehingga kadar sulfur yang dapat terlepas akan lebih banyak. Dari grafik juga terlihat bahwa laju alir umpan dengan kecepatan 0,3612 dengan kadar sulfur sisa sebesar $42,1653 \%$.

Tabel 6. Hubungan Pengaruh perbandingan Batubara : CPO terhadap Kadar sulfur

\begin{tabular}{cccccc}
\hline NO & $\begin{array}{c}\text { Batubara } \\
\text { : CPO }\end{array}$ & \multicolumn{4}{c}{ Kadar sulfur (\%) } \\
\hline 1 & $1: 2$ & 45,269 & 40,8267 & 29,5142 & 29,3007 \\
2 & $1: 4$ & 43,2643 & 38,9319 & 28,0977 & 26,4713 \\
3 & $1: 6$ & 42,1653 & 36,1296 & 25,3515 & 26,0713 \\
\hline
\end{tabular}

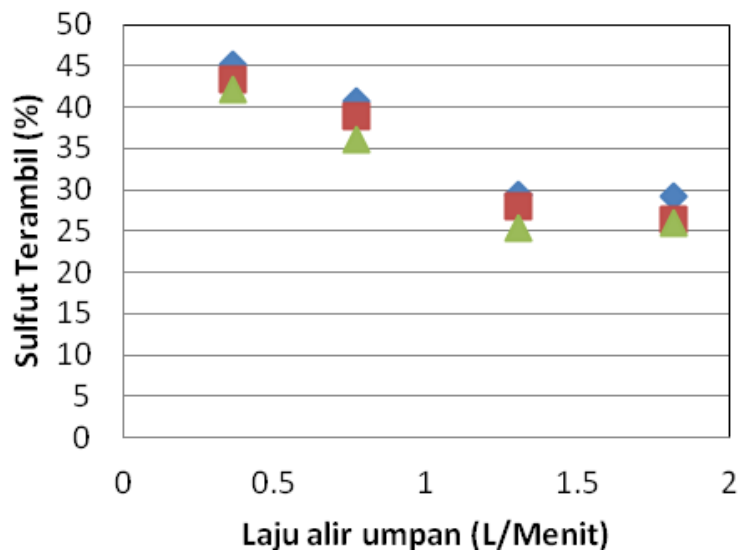

Gambar 8. Hubungan antara perbandingan Batubara : CPO dengan Sulfur terambil (\%)

Dari tabel 6 grafik 8 diatas terlihat bahwa penurunan kadar sulfur terbaik pada perbandingan 1 : 2 hal ini dikarenakan CPO yang ditambah kan lebih banyak sehingga pada CPO akan lebih banyak juga dapat terhidrolisa secara alami menjadi sufactan yang dapat menurunkan tegangan permukan.Senyawa sabun asam lemak ( $\mathrm{RCOOH})$ pada crude palm oil (CPO) dapat digunakan sebagai surfaktan dalam proses flotasi, 
mengingat struktur senyawa ini terdiri dari gugus anion(COO-) yang bersifat polar (hidrofilik) dan gugus rantai karbon (R) yang bersifat non polar (hidrofobik). Senyawa sabun tersebut dapat dihidrolisis basa dari minyak/lemak kasar kelapa sawit (CPO). Pada umumnya bilangan penyabunan CPO tergolong cukup tinggi yaitu sebesar 204,4 yang menunjukan kuantitas sabun asam lemak dalam CPO relatif tinggi dan sangat baik untuk proses flotasi. Asam lemak dari CPO dapat berfungsi dengan ganda baik sebagai kolektor maupun sebagai froter dalam sistem flotasi.

\section{Kesimpulan (Conclusion)}

1. Pengurangan kadar sulfur pada batubara dapat menggunakan metode flotasi.

2. Perbandingan jumlah CPO berpengaruh pada hasil pengurangan kadar sulfur pada batubara.

3. Kondisi yang optimal pada pengurangan kadar sulfur pada proses flotasi ketika laju alir umpan sebesar 0,3612 L/menit dengan perbandingan CPO/Batubara pada 1:2.

\section{Daftar Pustaka}

Aladin, Andi, 2009, Penentuan Rasio Optimum Campuran CPO : Batubara dalam Desulfurisasi dan Deashing secara Flotasi Kontinyu, Jurnal Rekayasa Proses, Vol.3, No.2.

Anonim, 2012, Desulfurisasi Mencegah Hujan Asam.

Brown,G.,G., 1973, Unit Operation .Edisi ke 13, John Willey \& Sons Inc., New York, PP:100-109.

Cahyadi, 2006, Strategi Menurunkan Emisi $\mathrm{SO}_{2}$ pada PLTU Batubara Yang Tidak Memiliki Desulfurisasi, Jurnal Ilmiah Teknologi Energi, Vol.1, No.2, Februari 2006.

Gaudin,A.M.,1957, Flotation, Mc.Graw-Hill Book Company Inc., Second edition, New York.

Krevelen,D.W.V., 1993, Coal: Typology - Phsycs Chemistry-Constitution, Third edition, Elsevier science publishers B.V Amsterdam.

Roesyadi ,A.,Mahfud.,dan Andi Aladin, 2005, Karakterisasi Desulfurisasi dan Deashing Batubara asal Sulawesi secara Flotasi, Jurnal terkreditasi Nasional "MEDIA TEKNIK "UGM Yogyakarta, No.1 Th XXVII Februari 2005 